\section{Agrostis Species Relationships Based on trnL-trnF and atpI-atpH Intergenic Spacer Regions}

\author{
Keenan Amundsen ${ }^{1}$ \\ Department of Agronomy and Horticulture, University of Nebraska, 377H \\ Plant Science Hall, Lincoln, NE 68583-0915
}

Scott Warnke

Floral and Nursery Plants Research Unit, U.S. Department of Agriculture, Beltsville, MD 20705

Additional index words. turfgrass, Agrostis, chloroplast, phylogeny

\begin{abstract}
The bentgrasses (Agrostis spp.) are among the most important species to the turfgrass industry. They have complex genomes resulting from polyploidization and high rates of interspecific hybridization. An understanding of species relationships would improve the efficiency of developing improved bentgrass cultivars. To elucidate the evolutionary relationships among Agrostis species, phylogenetic analyses were performed on sequences of two chloroplast-encoded intergenic spacer regions. A 298-bp region of the trnL-trnF intergenic spacer and a 451-bp region of the atpI-atpH intergenic spacer were included in the analyses. A total of 47 Agrostis accessions were included with both cultivated and unimproved material from the National Plant Germplasm System. Of these 47 Agrostis collections, there were 10 unique trnL-trnF haplotypes and eight distinct atpI-atpH haplotypes, indicating a high degree of shared sequence identity within these chloroplast intergenic regions. These findings suggest that the chloroplast genomes of $A$. canina and $A$. stolonifera are more closely related to each other than either species is to $A$. capillaris, incongruent with our previous understanding of genome relationships in the genus.
\end{abstract}

The bentgrasses (Agrostis spp.) are important species to the turfgrass industry because of their ability to form a dense, high-quality turf at low mowing heights. There are between 150 and 200 species of Agrostis (Harvey, 2007), and the evolutionary relationships between species are not clearly understood. Deducing these relationships is complicated by a number of factors. The major turf-type Agrostis species are highly outcrossing and exhibit high rates of heterozygosity (Warnke et al., 1998). Several species are polyploid causing homoeologous loci. Homologous genes often have high levels of sequence identity and may not be informative. Intermediate morphologies exist between taxa making taxonomic classification difficult. Interspecific hybridization is common and these reticulation events are difficult to represent in bifurcating phylograms.

Jones (1956a, 1956b, 1956c) described the chromosome pairing behavior during metaphase I of meiosis among Agrostis stolonifera, A. canina, A. capillaris, A. vinealis, and $A$. gigantea. Agrostis vinealis is an autotetraploidization of A. canina (Jones, 1956a) and these species have the genome designations $\mathrm{A}_{1} \mathrm{~A}_{1} \mathrm{~A}_{1} \mathrm{~A}_{1}$ and $\mathrm{A}_{1} \mathrm{~A}_{1}$, respectively

Received for publication 26 Aug. 2011. Accepted for publication 10 Nov. 2011.

${ }^{1}$ To whom reprint requests should be addressed; e-mailkamundsen2@unl.edu. from these Agrostis diversity studies, but there have been no studies designed to specifically explore these relationships.

Species relationships can be deduced from nuclear and plastid DNA sequences. Reichman et al. (2006) sequenced the chloroplast $m a t K$ gene and nuclear internal transcribed spacer(ITS) region from 19 Agrostis and three Polypogon accessions. Phylogenetic analysis of the DNA sequences was used to determine if transgenic A. stolonifera from a controlled area was capable of pollinating wild populations of related species growing at a distance. The individual phylogenies were used to distinguish Agrostis accessions by species. Certain Agrostis species have been included in phylogenies of the Aveneae and Poeae tribes based on DNA sequence data, placing Agrostis species sister to Calamagrostis and Polypogon species within the tribe Aveneae (Döring et al., 2007; Quintanar et al., 2007; Soreng et al., 2007).

Inference of Agrostis evolution, a highly outcrossing polyploid, based on ITS or other high copy-repetitive sequence elements, might not provide an accurate depiction of species evolution (Feliner and Rosselló, 2007) and single or low-copy nuclear genes might be more informative (Feliner and Rosselló, 2007; Sang, 2002). One drawback of using low copy genes is that they can be difficult to identify in non-model organisms such as Agrostis. Rotter et al. (2007) sequenced expressed sequence tag DNA libraries of the two Agrostis tetraploid species A. stolonifera and A. capillaris covering $\approx 10 \%$ of the predicted gene space. This sequencing effort led to the identification of 177 and 161 Oryza Conserved Ortholog Set (COS; Fulton et al., 2002) genes conserved in the $A$. capillaris and A. stolonifera DNA sequence libraries, respectively. Fulton et al. (2002) describe a reference set of 1025 COS genes that are single or low copy genes and conserved across diverse genomes. Seven of the 161 A. stolonifera and 11 of the 177 A. capillaris Oryza COS gene homologs were found to have conserved sequences in other grasses. These sequences were used in phylogenetic analyses that placed the Agrostis species closer to Festuca arundinacea than to Avena sativa, which is interesting because Agrostis is in the same tribe as $A$. sativa, whereas $F$. arundinacea is in the Poeae tribe. Agrostis was placed in the Aveneae tribe based on morphological characteristics and enzyme restriction patterns of chloroplast DNA (Soreng and Davis, 1998; Watson, 1990). The two tribes are closely related (Kellogg, 1998; Soreng et al., 2007) and share many common chloroplast DNA restriction sites (Soreng et al., 1990).

Chloroplast sequences would be more informative for deducing Agrostis relationships because chloroplasts are maternally inherited in Agrostis and have simple genomes (Warnke, 2003). Soreng et al. (2007) performed a phylogenetic analysis of the tribe Poeae using morphological characteristics and 
sequence data of three chloroplast-encoded genes, maturase $\mathrm{K}$ (matK), NADH dehydrogenase subunit $\mathrm{F}(n d h F)$, and ATP synthase beta subunit (atp $\beta$ ). The sequence data for this project are available through the National Center for Biotechnology Information databases and the analysis included the species Agrostis tenerrima Trin., Calamagrostis arundinacea (L.) Roth., C. canadensis (Michx.) P. Beauv., Polypogon monspeliensis, Festuca rubra L., and F. subverticillata (Pers.) E.B. Alexeev. Soreng et al. (2007) found that molecular character data were better than morphological data at describing a well-resolved set of species relationships. Similarly, Döring et al. (2007) sequenced the matK gene from a number of specimens from the Aveneae/ Poeae complex including $A$. capillaris, $C$. rivalis (Torges) H. Scholz., C. macrolepis Litv., Apera spica-venti (L.) P. Beauv., P. monspeliensis, Avena sativa L., F. altissima All., and F. gigantean (L.) Vill. Agrostis can hybridize with Polypogon spp. and shares morphological characteristics in common with Apera and Calamagrostis spp. (Harvey, 2007). The results of Döring et al. (2007) were consistent with Soreng et al. (2007) and it is interesting that both phylogenies of chloroplast-encoded gene sequence data placed Agrostis more closely to Avena than Festuca in contrast to the COS phylogenetic analysis performed by Rotter et al. (2007).

Different homologous DNA segments from related taxa often have inconsistent evolutionary histories and analyzing the DNA segments separately will often yield trees of differing topologies (McBreen and Lockhart, 2006). These inconsistencies may arise from reticulation events such as horizontal gene transfer, recombination, and hybridization that are not well represented by bifurcating phylogenetic trees (Huson and Bryant, 2006; Huson et al., 2005; Linder and Rieseberg, 2004). A phylogenetic network might be the best representation of the evolution of Agrostis, because a number of Agrostis species are polyploids and thought to have evolved from naturally occurring interspecific hybrids (Casler and Duncan, 2003). The software program SplitsTree4 can render phylogenetic networks from individual gene trees (Huson and Bryant, 2006).

Since the 1956 cytological experiments of Jones, there have been a number of advancements for investigating relationships between Agrostis species, particularly with the use of molecular markers, sequence data, and phylogenetic analyses. Genetic relationships in Agrostis have been studied using nuclear markers (Amundsen and Warnke, 2011; Vergara and Bughrara, 2003), but the focus of these studies was to resolve genetic diversity. Agrostis has been included in other phylogenetic studies of the tribe Poeae and Aveneae (Döring et al., 2007; Quintanar et al., 2007; Soreng et al., 2007), but to date, there are no studies focused on resolving evolutionary relationships within
Agrostis based on chloroplast sequences. In the present study, the chloroplast encoded trnL-trnF and atpI-atpH intergenic spacer regions were sequenced from a diverse set of Agrostis germplasm to study the relationships between accessions. Phylogenies of both cultivated and non-cultivated National Plant Germplasm System Agrostis accessions were compared to identify any incongruence and infer species relationships. Species relationships are complex in Agrostis, but a better understanding will assist plant breeders in maximizing wide crossbreeding, identify bridging species to introgress important traits, identify evolutionary events that have led to important turf characteristics, and resolve polyploidization events in the genus.

\section{Materials and Methods}

Plant material and DNA extraction. Accessions of Agrostis were chosen that represent cultivated and non-cultivated accessions, various ploidy levels as predicted by flow cytometry, different species, and different geographic regions (Table 1). Seeds of each accession were obtained from the National Plant Germplasm System, Dr. Doug Johnson (Forage and Range Research Laboratory, U.S. Department of Agriculture), or from the National Turfgrass Evaluation Program. Seeds were planted in Premier Pro-Mix BX soil (Premier Horticulture Inc., Quakertown, PA) in 2.5-cm-diameter Cone-tainers (Stuewe and Sons, Tangent, OR) and maintained in a temperature-controlled greenhouse on

Table 1. Accessions used in phylogenetic analyses.

\begin{tabular}{|c|c|c|c|c|}
\hline Study ID & Accession & Taxon & Cultivar $^{z}$ & Origin \\
\hline$\overline{\text { aint-1 }}$ & PI203444 & Apera interrupta & & Turkey \\
\hline aint-2 & PI204389 & Apera interrupta & & Turkey \\
\hline pchi-1 & PI372227 & Polypogon chilensis & & Uruguay \\
\hline pvir-1 & PI204395 & Polypogon viridis & & Turkey \\
\hline pvir-2 & PI223241 & Polypogon viridis & & Afghanistan \\
\hline acan-10 & PI189141 & Agrostis canina & Novobent & Netherlands \\
\hline acan-11 & PI290707 & Agrostis canina & & United Kingdom \\
\hline acap-7 & PI237717 & Agrostis capillaris & Odenwalder & Germany \\
\hline acap-25 & PI578528 & Agrostis capillaris & Exeter & United States \\
\hline acap-26 & PI600936 & Agrostis capillaris & Duchess & United Kingdom \\
\hline acas-11 & PI240132 & Agrostis castellana & & Portugal \\
\hline acas-3 & PI318928 & Agrostis castellana & & Spain \\
\hline acas- 8 & PI469217 & Agrostis castellana & Highland & United States \\
\hline acla-2 & PI632584 & Agrostis clavata & & Mongolia \\
\hline acla-5 & W621240 & Agrostis clavata & & Mongolia \\
\hline agig-77 & PI251099 & Agrostis gigantea & & Yugoslavia \\
\hline alim-1 & W623620 & Agrostis limprichtii & & China \\
\hline alya-1 & PI636652 & Agrostis lyallii & & New Zealand \\
\hline amon-3 & PI632549 & Agrostis mongolica & & Mongolia \\
\hline amon-5 & W619706 & Agrostis mongolica & & Mongolia \\
\hline amun-7 & PI230236 & Agrostis munroana & & Iran \\
\hline apal-1 & PI238226 & Agrostis pallida & & Spain \\
\hline asp-4 & PI502279 & Agrostis sp. & & Russian \\
\hline asto-36 & PI578529 & Agrostis stolonifera & Seaside & United States \\
\hline asto-40 & PI632687 & Agrostis stolonifera & Penncross & United States \\
\hline asto-19 & PI204390 & Agrostis stolonifera & & Turkey \\
\hline asto-23 & PI251945 & Agrostis stolonifera & & Austria \\
\hline asto-29 & PI302902 & Agrostis stolonifera & & Spain \\
\hline asto-30 & PI318934 & Agrostis stolonifera & & Spain \\
\hline asto-34 & PI531251 & Agrostis stolonifera & Keszthelyi4 & Hungary \\
\hline atri-1 & PI598462 & Agrostis trinii & & Russian \\
\hline atri-2 & PI632559 & Agrostis trinii & & Mongolia \\
\hline atri-3 & PI636572 & Agrostis trinii & & Mongolia \\
\hline atri-4 & W619572 & Agrostis trinii & & Mongolia \\
\hline avin-1 & PI440110 & Agrostis vinealis & & Russian \\
\hline agig-1 & RUS-07-01-002 & Agrostis gigantea & & Russia \\
\hline agig-5 & RUS-07-12-041 & Agrostis gigantea & & Russia \\
\hline agig-12 & RUS-07-32-131 & Agrostis gigantea & & Russia \\
\hline asto-1 & KGZ-06-08-051 & Agrostis stolonifera & & Kyrgyzstan \\
\hline agig-47 & PRC-06-IN/118-402 & Agrostis gigantea & & China \\
\hline asto-3 & NT-1998-26 & Agrostis stolonifera & Penn G-1 & United States \\
\hline asto- 4 & NT-1998-27 & Agrostis stolonifera & Penn A-4 & United States \\
\hline asto-5 & NT-1998-29 & Agrostis stolonifera & Penn A-2 & United States \\
\hline asto-6 & NT-2003-2 & Agrostis stolonifera & Penn A-1 & United States \\
\hline asto-7 & NT-2003-6 & Agrostis stolonifera & Alpha & United States \\
\hline asto-9 & NT-2003-10 & Agrostis stolonifera & Declaration & United States \\
\hline asto-12 & NT-2003-15 & Agrostis stolonifera & Kingpin & United States \\
\hline asto-13 & NT-2003-21 & Agrostis stolonifera & 007 & United States \\
\hline acan-2 & NT-1998-11 & Agrostis canina & Vesper (Pick MVB) & United States \\
\hline acan-6 & NT-2003-16 & Agrostis canina & Villa (IS-AC 1) & United States \\
\hline acan-7 & NT-2003-18 & Agrostis canina & Venus (EFD) & United States \\
\hline acan-8 & NT-2003-19 & Agrostis canina & Vesper & United States \\
\hline
\end{tabular}

${ }^{\mathrm{z}}$ Cultivar $=$ cultivated accessions are indicated by their cultivar name. 
a 12-h photoperiod with $24{ }^{\circ} \mathrm{C}$ day and $21{ }^{\circ} \mathrm{C}$ night temperatures. Total DNA was extracted from a single genotype of each accession by either the DNeasy 96 Plant kit (Qiagen, Valencia, CA) or by a modified $\mathrm{CTAB}$ method (Amundsen et al., 2011).

Conserved chloroplast primer screen. The Agrostis stolonifera L. cv. Penn-A4 chloroplast genome (EF115543) was obtained from GenBank. Chloroplast-specific primer sequences reported by Shaw et al. (2005, 2007) and Small et al. (1998) were computationally screened against the $A$. stolonifera chloroplast genome in LaserGene (DNASTAR Inc., Madison, WI). Conserved primer pairs are shown in Table 2. A polymerase chain reaction (PCR) protocol consisting of denaturing the sample at $95.0{ }^{\circ} \mathrm{C}$ for $5.0 \mathrm{~min}$ followed by 35 cycles of $95.0{ }^{\circ} \mathrm{C}$ for 1.0 $\min , 45.0^{\circ} \mathrm{C}$ for $45.0 \mathrm{~s}$, and $72.0^{\circ} \mathrm{C}$ for 1.5 min followed by holding the sample at $72.0^{\circ} \mathrm{C}$ for $5.0 \mathrm{~min}$ was used to test the conserved primer pairs against a panel of Agrostis germplasm. Each PCR reaction contained 1.0 units recombinant Taq DNA Polymerase (Invitrogen, Carlsbad, CA), $20 \mathrm{~mm}$ Tris $\mathrm{pH}$ 8.4, $50 \mathrm{~mm} \mathrm{KCl}, 1.5 \mathrm{~mm} \mathrm{MgCl} 2,0.25 \mathrm{~mm}$ each dNTP (Promega, Madison, WI), $0.5 \mu \mathrm{M}$ each primer, and $20 \mathrm{ng}$ template DNA.

The software program DNASTAR Lasergene Version 6 was used to identify conserved chloroplast-specific primer pairs reported by Shaw et al. $(2005,2007)$ and Small et al. (1998) in an Agrostis stolonifera cv. Penn-A4 chloroplast genome (GenBank Accession EF115543). Seventeen conserved primer pairs were identified and their relative base pair position on the chloroplast genome was determined (Table 2). A subset of conserved primer pairs was screened on a diverse panel of Agrostis DNA and successfully amplified products sequenced. The primer pairs amplifying the $t r n L-t r n F$ and atpI-atpH intergenic spacer regions of the chloroplast genome amplified well in all accessions tried and were subsequently sequenced from the 52 accessions composed of one Apera accession, three Polypogon accessions, and 48 Agrostis accessions (Table 1).

DNA sequencing and phylogenetic analysis. All sequencing reactions of atpI-atpH and $\operatorname{trn} L-\operatorname{trn} F$ intergenic spacer regions were performed using the BigDye3.1 sequencing kit (Applied Biosystems, Foster City, CA). Sequencing reactions were run separately for each primer specified by the $\mathrm{A}$ and $\mathrm{K}$ primer group identifier in Table 2 and on a GeneAmp2700 ThermalCycler (Applied Biosystems). Sequences were aligned with ClustalW2.0.9 (Thompson et al., 1994) and manually adjusted to further optimize alignments. Different methods were tested for encoding insertions and deletions in the alignments, including the complete omission of the gapped regions, the replacement of gap characters by a fifth base, the treatment of gaps as missing data, and the Barriel method (Barriel, 1994). The Barriel method encodes gapped regions with multistate characters to account for informative gaps in the data matrix.

Table 2. Primers conserved in the Agrostis stolonifera chloroplast genome.

\begin{tabular}{|c|c|c|c|c|c|}
\hline$\overline{\mathrm{ID}^{\mathrm{z}}}$ & $\mathrm{Name}^{\mathrm{y}}$ & Position $^{\mathrm{x}}$ & Sequence $5^{\prime}-3^{\prime}$ & $\mathrm{Tm}^{\mathrm{w}}$ & $\operatorname{Ref}^{v}$ \\
\hline \multirow[t]{2}{*}{$\overline{\mathrm{A}}$} & trnL-trnFspacer: $\mathrm{E}$ & 47467 & GGTTCAAGTCCCTCTATCCC & 49.1 & THI \\
\hline & trnL-trnFspacer:F & 47888 & ATTTGAACTGGTGACACGAG & 47.1 & THI \\
\hline \multirow[t]{2}{*}{ B } & trnT-trnLspacer:A & 46123 & CATTACAAATGCGATGCTCT & 48.0 & THI \\
\hline & trnT-trnLspacer:B & 47003 & TCTACCGATTTCGCCATATC & 49.4 & THI \\
\hline \multirow[t]{2}{*}{$\mathrm{C}$} & $\mathrm{rpS} 16 \mathrm{R}$ & 5218 & AACATCWATTGCAASGATTCGATA & 55.3 & THII \\
\hline & $\mathrm{rpS16F}$ & 6105 & AAACGATGTGGTARAAAGCAAC & 50.5 & THII \\
\hline \multirow[t]{2}{*}{$\mathrm{D}$} & $3^{\prime} \operatorname{trn} G^{\mathrm{UUC}}$ & 13397 & GTAGCGGGAATCGAACCCGCATC & 64.2 & THII \\
\hline & $5^{\prime} \operatorname{trnG} 2 \mathrm{G}$ & 14137 & GCGGGTATAGTTTAGTGGTAAAA & 49.7 & THII \\
\hline \multirow[t]{2}{*}{$\mathrm{E}$} & $\operatorname{trnC}{ }^{\mathrm{GCA}} \mathrm{R}$ & 18642 & CACCCRGATTYGAACTGGGG & 54.1 & THII \\
\hline & rpoB & 19952 & CKACAAAAYCCYTCRAATTG & 46.7 & THII \\
\hline \multirow[t]{5}{*}{$\mathrm{F}$} & psbMR & 17235 & $\begin{array}{l}\text { ATGGAAGTAAATATTCTYGCA } \\
\text { TTTATTGCT }\end{array}$ & 49.7 & THII \\
\hline & $\operatorname{trnD}{ }^{\mathrm{GUC}} \mathrm{R}$ & 16464 & GGGATTGTAGYTCAATTGGT & 45.5 & THII \\
\hline & ycf6R & 17690 & GCCCAAGCRAGACTTACTATATCCAT & 57.3 & THII \\
\hline & $\operatorname{trnC} C^{\mathrm{GCA}} \mathrm{F}$ & 18659 & CCAGTTCRAATCYGGGTG & 45.2 & THII \\
\hline & ycf6F & 17715 & ATGGATATAGTAAGTCTYGCTTGGGC & 57.3 & THII \\
\hline \multirow[t]{4}{*}{ G } & $\operatorname{trn} E^{\mathrm{UUC}}$ & 15972 & AGGACATCTCTCTTTCAAGGAG & 48.6 & THII \\
\hline & $\operatorname{trnT} T^{\mathrm{GGU}}$ & 15369 & CTACCACTGAGTTAAAAGGG & 43.4 & THII \\
\hline & $\operatorname{trnD^{\mathrm {GUC}}\mathrm {F}}$ & 16483 & ACCAATTGAACTACAATCCC & 45.5 & THII \\
\hline & $\operatorname{trn} Y^{\mathrm{GUA}}$ & 16164 & CCGAGCTGGATTTGAACCA & 53.3 & THII \\
\hline \multirow[t]{2}{*}{$\mathrm{H}$} & rpS4R2 & 45605 & CTGTNAGWCCRTAATGAAAACG & 49.2 & THII \\
\hline & $\operatorname{trnT}{ }^{\mathrm{UGU}} \mathrm{R}$ & 46147 & AGGTTAGAGCATCGCATTTG & 49.7 & THII \\
\hline \multirow[t]{2}{*}{ I } & $\operatorname{trnL}^{\prime \mathrm{UAA}} \mathrm{F}(\mathrm{TabC})$ & 46991 & CGAAATCGGTAGACGCTACG & 52.7 & THII \\
\hline & $3^{\prime} \operatorname{trnL} L^{\mathrm{UAA}} \mathrm{R}(\mathrm{TabD})$ & 47487 & GGGGATAGAGGGACTTGAAC & 49.1 & THII \\
\hline \multirow[t]{2}{*}{$\mathrm{J}$} & $\mathrm{psbB}$ & 70842 & TCCAAAAANKKGGAGATCCAAC & 54.5 & THII \\
\hline & $\mathrm{psbH}$ & 71468 & TCAAYRGTYTGTGTAGCCAT & 50.4 & THII \\
\hline \multirow[t]{2}{*}{$\mathrm{K}$} & atpI & 31735 & TATTTACAAGYGGTATTCAAGCT & 50.2 & THIII \\
\hline & atpH & 32393 & CCAAYCCAGCAGCAATAAC & 48.0 & THIII \\
\hline \multirow[t]{2}{*}{$\mathrm{L}$} & ndhC & 50106 & $\begin{array}{l}\text { TATTATTAGAAATGYCCARA } \\
\text { AAATATCATATTC }\end{array}$ & 53.8 & THIII \\
\hline & $\operatorname{trn} \mathrm{V}^{(\mathrm{UAC})} \mathrm{x} 2$ & 51106 & GTCTACGGTTCGARTCCGTA & 49.3 & THIII \\
\hline \multirow[t]{2}{*}{ M } & psbE & 62673 & TATCGAATACTGGTAATAATATCAGC & 46.6 & THIII \\
\hline & petL & 64048 & AGTAGAAAACCGAAATAACTAGTTA & 45.9 & THIII \\
\hline \multirow[t]{2}{*}{$\mathrm{N}$} & rpL32-F & 105950 & CAGTTCCAAAAAAACGTACTTC & 48.2 & THIII \\
\hline & $\operatorname{trn} L^{(\mathrm{UAG})}$ & 106833 & CTGCTTCCTAAGAGCAGCGT & 51.7 & THIII \\
\hline \multirow[t]{2}{*}{$\mathrm{O}$} & $\operatorname{rpS16x1}$ & 6084 & GTTGCTTTYTACCACATCGTTT & 50.5 & THIII \\
\hline & $\operatorname{trn} Q^{(\mathrm{UUG})}$ & 6978 & GCGTGGCCAAGYGGTAAGGC & 59.1 & THIII \\
\hline \multirow[t]{2}{*}{$\mathrm{P}$} & TabE & 47467 & GGTTCAAGTCCCTCTATCCC & 49.1 & THIII \\
\hline & ndhJ & 48565 & ATGCCYGAAAGTTGGATAGG & 48.5 & THIII \\
\hline \multirow[t]{2}{*}{ Q } & $\operatorname{trn} \mathrm{T}^{(\mathrm{GGU})}-\mathrm{R}$ & 15350 & CССTTTTAACTCAGTGGTAG & 43.4 & THIII \\
\hline & $\mathrm{psbD}$ & 9263 & CTCCGTARCCAGTCATCCATA & 49.2 & THIII \\
\hline
\end{tabular}

${ }^{\mathrm{z}} \mathrm{ID}=$ primer group identifier.

${ }^{\mathrm{y}} \mathrm{Name}=$ name of the polymerase chain reaction primer.

${ }^{\times}$Position = primer location on the Agrostis stolonifera Penn A-4 chloroplast genome.

${ }^{\mathrm{w}} \mathrm{Tm}=$ The DNASTAR Lasergene Version 6 predicted melting temperature of the polymerase chain reaction primer.

${ }^{\vee}$ Ref $=$ Reference source for the primers THI (Small et al., 1998), THII (Shaw et al., 2005), and THIII (Shaw et al., 2007).

Apera accessions aint-1 and aint-2 defined the outgroup in all phylogenetic analyses.

Maximum parsimony and maximum likelihood analyses were performed using the software program PAUP* Version $4.0 \mathrm{~b} 10$ (Swofford, 2002) and Bayesian analysis was done using MrBayes Version 3.1.2 (Huelsenbeck and Ronquist, 2001; Ronquist and Huelsenbeck, 2003). Maximum parsimony analysis was performed using a heuristic search with random addition of sequences. The most likely model of evolution was determined using ModelTest3.7 (Posada and Crandall, 1998) and implemented in both maximum likelihood and Bayesian phylogenetic analyses. Bayesian analysis was run for 1,000,000 MCMC generations and sampled after every 100 . The average SD of split 
frequencies between the independent analyses for each of the chloroplast DNA regions was below 0.01, suggesting high confidence of convergence. Bootstrap analysis was run on both the maximum parsimony $(10,000$ replicates) and maximum likelihood (1,000 replicates) analyses. Splitstree4 was used to build consensus networks from multiple gene trees to identify discordances between phylogenies with default threshold and edge weight parameters. The split graph was drawn as a rectangular cladogram using the cluster network split transformation.

\section{Results}

The alignment of a 298-bp conserved region of the trnL-trnF intergenic spacer region was used in the phylogenetic analyses. This region contains two gaps and 38 variable sites, 32 of which are parsimonyinformative $(10.7 \%$ of bps). Thirteen unique haplotypes were identified in the set of 52 accessions (Table 3). Similarly, alignment of a 451-bp conserved region of the atpI-atpH intergenic spacer region had 12 gaps and 58 variable sites, 48 of which are parsimonyinformative ( $10.6 \%$ of bps). There were 11 distinct haplotypes (Table 4) of the atpIatpH intergenic spacer region.

A phylogenetic analysis of the atpI-atpH and $\operatorname{trn} L$-trnF intergenic spacer regions was performed separately on the cultivated Agrostis accessions from Table 1 along with the Polypogon and Apera accessions or on the full set of 52 accessions listed in Table 1. Of the four gap-encoding methods, complete omission of the gapped regions reduced the number of atpI-atpH haplotypes from 11 to nine and trnL-trnF haplotypes from 13 to 11 . The other three methods: new state, missing, and the Barriel method, resulted in similar phylogenies so the Barriel method was chosen because it effectively represents informative gaps. The predicted model of evolution for both the trnL-trnF and atpI-atpH regions was a general time reversible model with equal base frequencies.

Maximum parsimony analysis of the $\operatorname{trnL-trnF}$ region for the set of 52 accessions gave a single most parsimonious tree with a length of 45 , consistency index of 0.9778 , and homoplasy index of 0.0222 (Fig. 1). Maximum parsimony analysis of the atpIatpH region for the same taxa gave a single most parsimonious tree with length of 79 , a consistency index of 0.9367 , and homoplasy index of 0.0633 (Fig. 2). All three phylogenetic analysis methods, maximum parsimony, maximum likelihood, and Bayesian inference, gave topologically similar trees for both intergenic spacer regions.

A maximum parsimony analysis of the trnL-trnF region from cultivated Agrostis accessions (Table 1) had a single best tree of length of 30 , consistency index of 1.0 , and homoplasy index of 0.0 (Fig. 3). The maximum parsimony phylogeny of the atpI-atpH region had a length of 42 , consistency index of 1.0, and homoplasy index of 0.0 (Fig. 4). Maximum parsimony, maximum likelihood,
Table 3. Unique trnL-trnF intergenic spacer haplotype.

\begin{tabular}{ll}
\hline Representative group ID & Accessions with identical haplotypes \\
\hline aint-1 & aint-1, aint-2 \\
pchi-1 & pchi-1 \\
pvir-1 & pvir-1, pvir-2 \\
acan-10 & acan-10, acan-11, agig-1, acan-2, acan-6, acan-7, acan-8 \\
acap-7 & acap-7, acap-25, acap-26, acas-11, acas-3, acas-8, apal-1, \\
& asto-29, asto-30, atri-1, agig-5, agig-12 \\
acla-2 & acla-2, amon-3, amon-5, atri-2, atri-4 \\
acla-5 & acla-5, agig-77, asp-4, atri-3, avin-1, asto-1, agig-47 \\
alim-1 & alim-1 \\
alya-1 & alya-1 \\
amun-7 & amun-7 \\
asto-36 & asto-36, asto-40, asto-19, asto-34, asto-3, asto-4, asto-5, \\
& asto-6, asto-7, asto-9, asto-13 \\
asto-23 & asto-23 \\
asto-12 & asto-12 \\
\hline
\end{tabular}

Table 4. Unique atpI-atpH intergenic spacer haplotypes.

\begin{tabular}{ll}
\hline Representative group ID & Accessions with identical haplotypes \\
\hline $\begin{array}{l}\text { aint-1 } \\
\text { pchi-1 } \\
\text { pvir-1 } \\
\text { acan-10 }\end{array}$ & aint-1, aint-2 \\
& pvir-1, pvir-2 \\
& acan-10, acan-11, acla-5, agig-77, asp-4, asto-40, asto-23, asto-34, \\
acap-7 & atri-3, avin-1, agig-1, asto-1, agig-47, asto-4, asto-5, asto-6, asto-7, \\
& acap-7, acap-25, acap-26, acas- 11 , acan-7, acas-8, apal-1, asto-29, asto-30, \\
acas-3 & atri-1, agig-5, agig-12 \\
acla-2 & acas-3 \\
alim-1 & acla-2, amon-3, amon-5, atri-2, atri-4 \\
alya-1 & alim-1 \\
amun-7 & alya-1 \\
asto-36 & amun-7 \\
& asto-36, asto-19, asto-3, asto-9
\end{tabular}

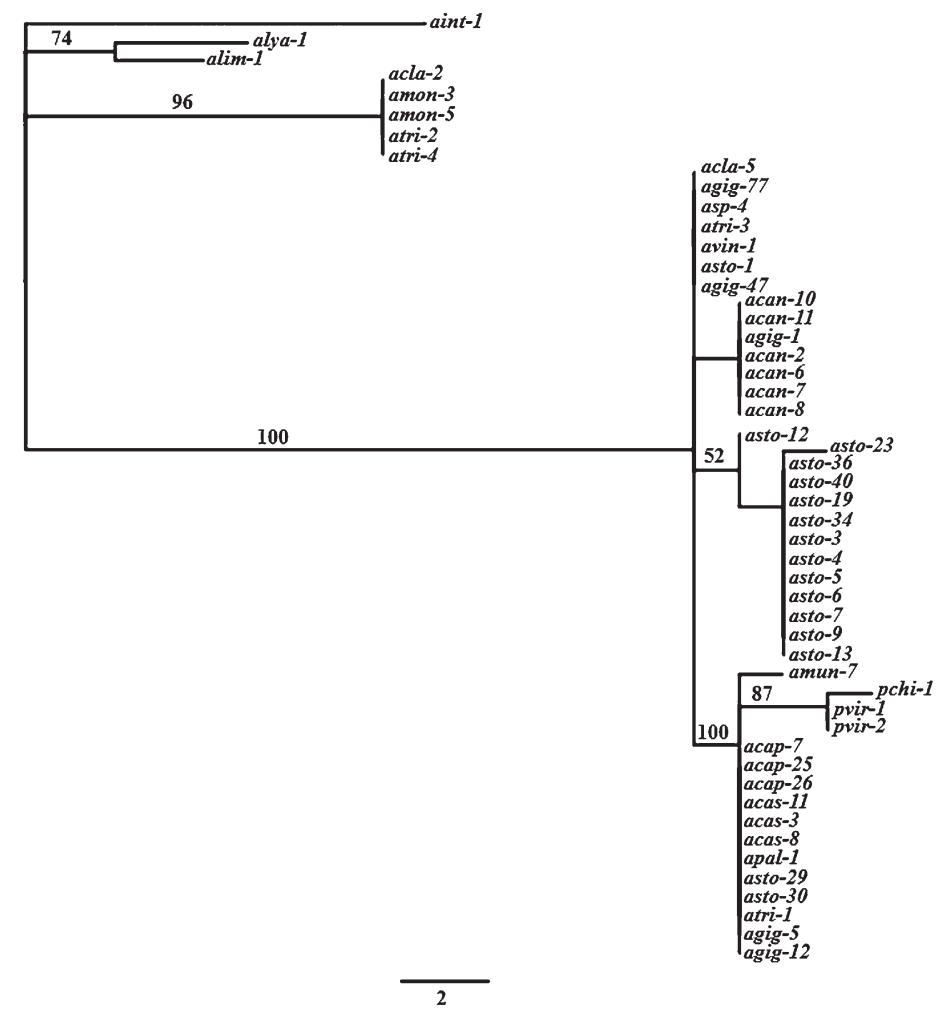

Fig. 1. Maximum parsimony phylogenetic analysis of the trnL-trnF intergenic spacer. The most parsimonious tree from the maximum parsimony analysis. The bootstrap support values greater than 50 from the parsimony analysis are indicated. 


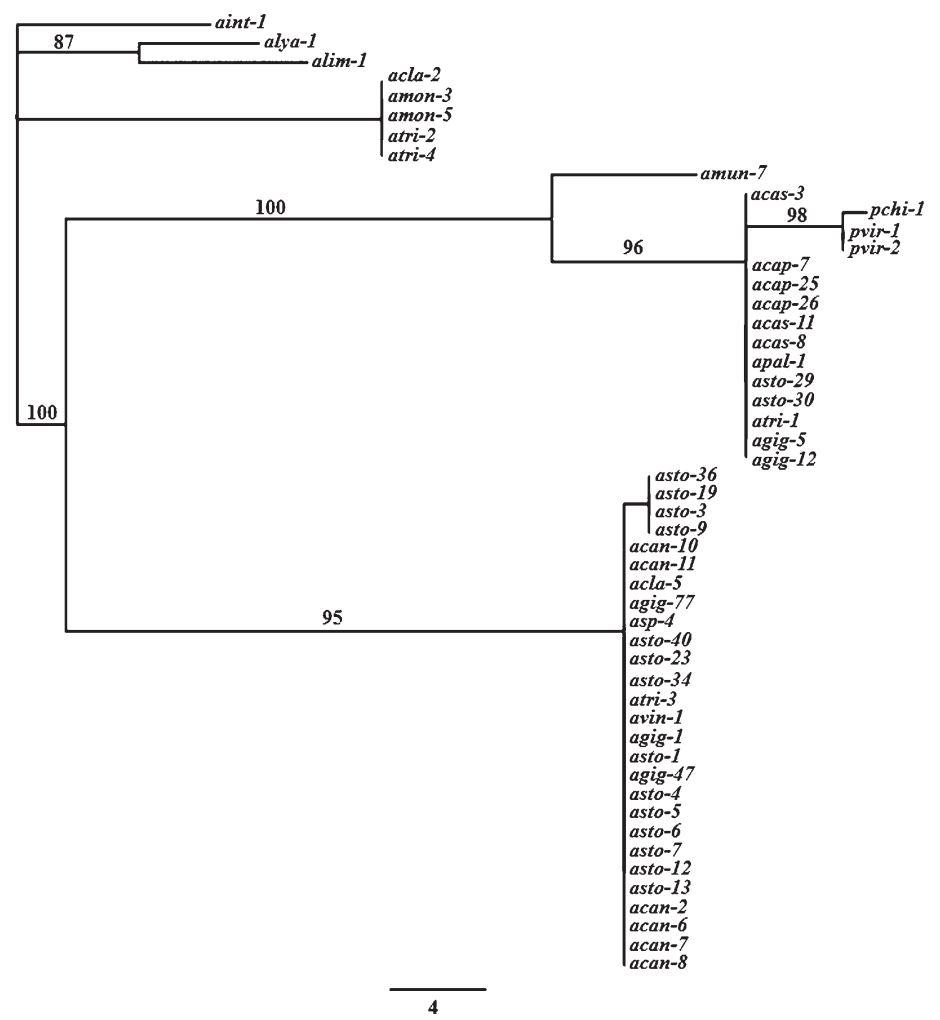

Fig. 2. Maximum parsimony phylogenetic analysis of the atpI-atpH intergenic spacer. The most parsimonious tree from the maximum parsimony analysis. The bootstrap support values greater than 50 from the parsimony analysis are indicated.

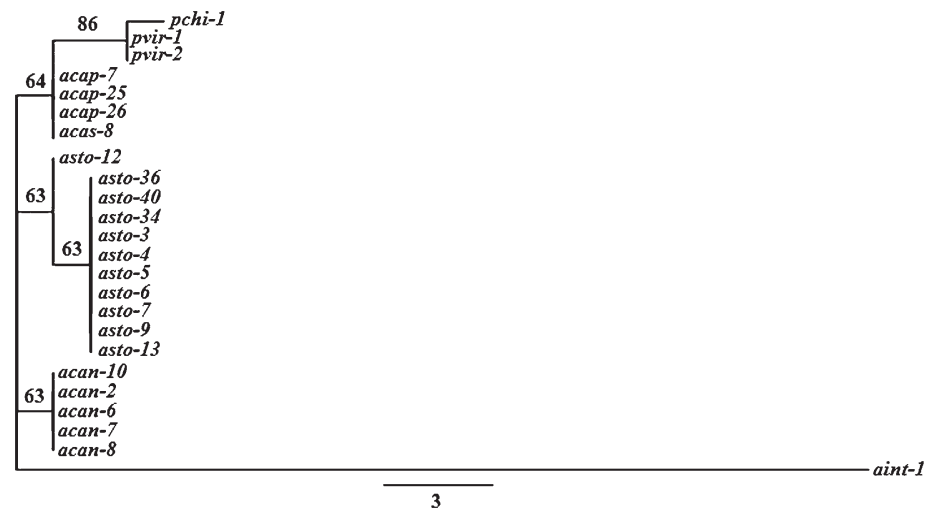

Fig. 3. Maximum parsimony phylogenetic analysis of the $\operatorname{trn} L-\operatorname{trn} F$ intergenic spacer from cultivated Agrostis spp. The most parsimonious tree from the maximum parsimony analysis. The bootstrap support values greater than 50 from the parsimony analysis are indicated.

and Bayesian inference gave topologically similar trees for both intergenic spacer regions. Both the trnL-trnF and atpI-atpH intergenic spacer regions divided the accessions into five distinct clades. The Polypogon accessions formed a single clade that is closely related to the clade representing the A. capillaris and $A$. castellana accessions. The remaining $A$. stolonifera and $A$. canina accessions formed two more groups. The atpI-atpH intergenic spacer region was not successful at distinguishing the $A$. canina accessions from the $A$. stolonifera accessions. The A. stolonifera accessions asto-3, asto-9, and asto-36 formed a distinct subgroup within the $A$. stolonifera and $A$. canina accessions. The $\operatorname{trn} L-\operatorname{trn} F$ spacer region was able to distinguish the $A$. canina accessions from the $A$. stolonifera accessions forming two distinct clades.

A Splitstree4 consensus network of the chloroplast-encoded intergenic spacer regions showed one disagreement; the placement of amun-7 was inconsistent between the individual sequence phylogenies (Fig. 5). One difference between the individual chloroplast DNA sequence analyses of the placement of amun-7 is in its relationship to the $A$. stolonifera and $A$. canina accessions. The analysis of the trnL-trnF region supports a closer relationship of amun-7 to the $A$. stolonifera and $A$. canina accessions com- pared with the same relationships from the atpI-atpH phylogeny.

\section{Discussion}

Polyploidization events, origins of turftype species, sources of novel germplasm, and targets for developing interspecific hybrids may be inferred from the evolution of Agrostis species. Chloroplast DNA sequence regions have been used to resolve phylogenies of several grass species (Fortune et al., 2008; Ge et al., 2002; Gillespie et al., 2006; Guo and Ge, 2005). There were only a few distinct haplotypes of the trnL-trnF and atpI-atpH intergenic spacer regions within this set of Agrostis, and therefore these chloroplast regions might not provide a detailed view of evolutionary processes in Agrostis. Another possibility is that the chloroplast genomes among Agrostis share a high degree of sequence identity, which would make it difficult to resolve species relationships using chloroplast-based sequence data.

The lack of cohesion of species in the individual chloroplast sequence-based phylogenies calls into question the ability to resolve species relationships using these chloroplast-encoded DNA sequences. For example, asto-1, asto-29, and asto-30 do not fall into or near the same clade as the rest of the A. stolonifera accessions. Similarly, the four $A$. trinii accessions and the five $A$. gigantea accessions are distributed throughout the phylogenetic tree and do not appear to be closely related. There are several possible reasons for this inability to distinguish species based on chloroplast sequence data, including incorrect accession identification in the National Plant Germplasm System. Additionally, multiple origins of a single species could result in different maternal chloroplast ancestral genomes. The possibility also exists that the chloroplast regions examined do not accurately reflect chloroplast evolution.

The phylogenetic analysis of the atpIatpH and trnL-trnF intergenic spacer regions of cultivated Agrostis accessions included four Agrostis species along with the Apera and Polypogon accessions. It is interesting that the Polypogon accessions are closely related to the $A$. capillaris accessions. Because Polypogon species are known to form intergeneric hybrids with Agrostis species (Barkworth, 2007), they may have evolved from a common ancestor. Furthermore, it is believed that the genome of the diploid $A$. canina contributed to the evolution of $A$. capillaris but not $A$. stolonifera. The data presented by these chloroplast phylogenies suggest that $A$. canina is more closely related to A. stolonifera than A. capillaris. Further experiments examining other chloroplast genome regions or nuclear COS DNA sequences may help to further resolve species relationships in Agrostis. An understanding of these relationships is important to turfgrass breeders because they can incorporate related material directly into breeding programs, recreate evolutionary events that led to the 


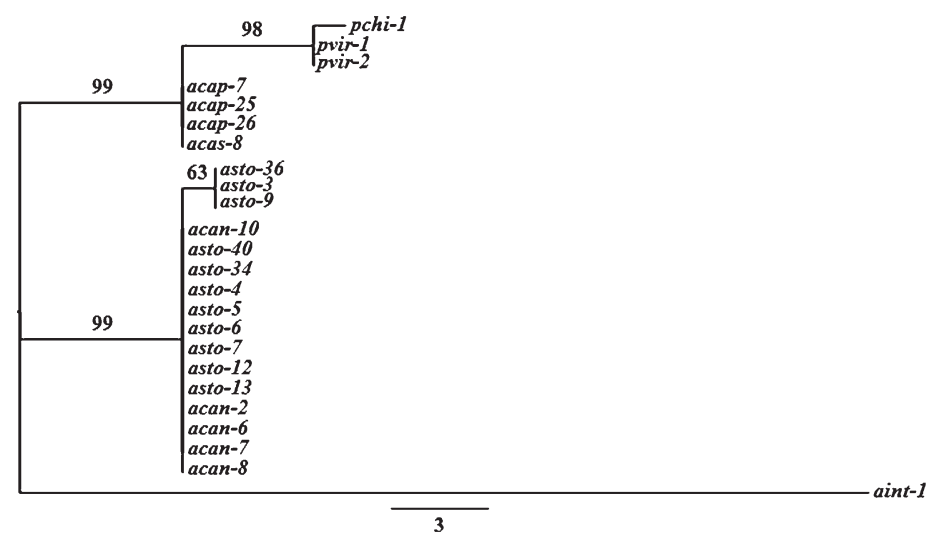

Fig. 4. Maximum parsimony phylogenetic analysis of the atpI-atpH intergenic spacer from cultivated Agrostis spp. The most parsimonious tree from the maximum parsimony analysis. The bootstrap support values greater than 50 from the parsimony analysis are indicated.

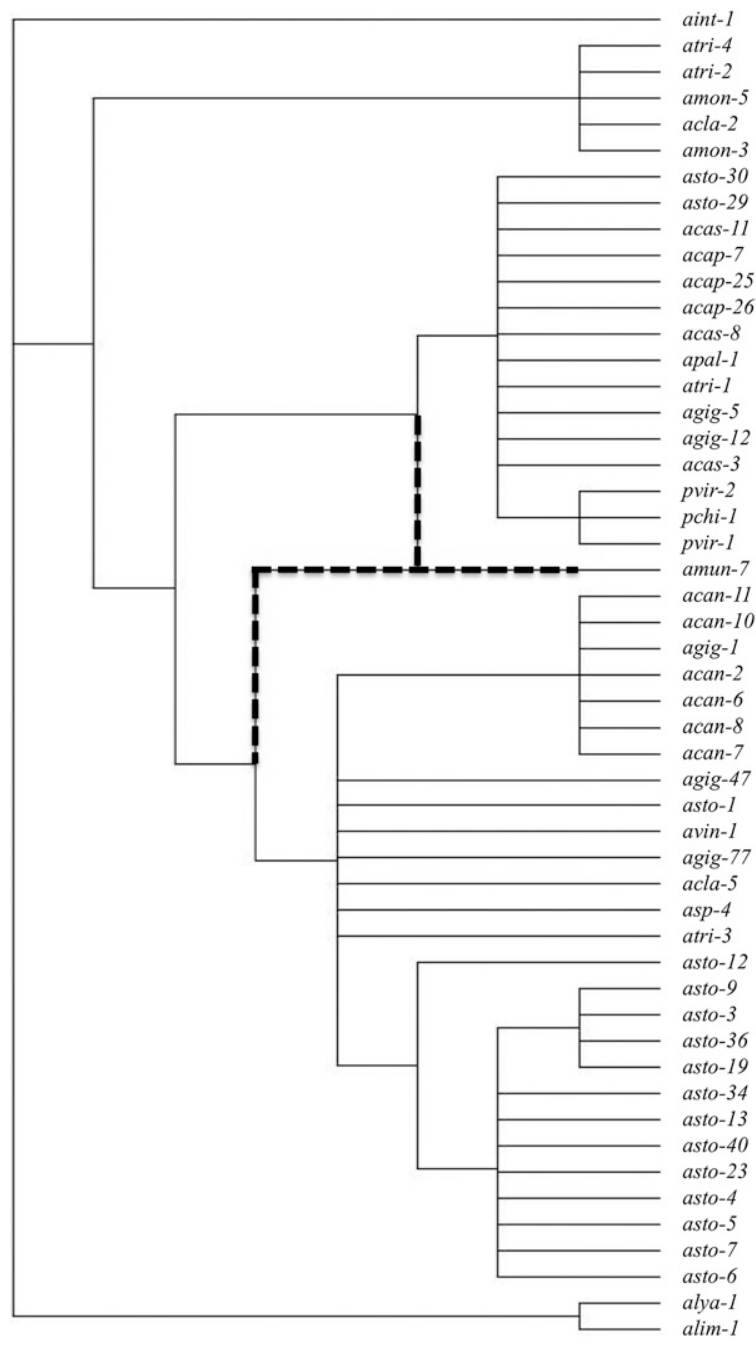

$\longmapsto 10.0$

Fig. 5. Consensus network of the atpI-atpH and trnL-trnF intergenic spacer regions. Splits are indicated with the bold dashed line.

high-quality turf-type Agrostis, or introduce novel stress tolerance genes through wide crossbreeding. This study provides valuable information to Agrostis breeders on species relationships and potential sources of novel

\section{Literature Cited}

Amundsen, K., D. Rotter, H.M. Li, J. Messing, G. Jung, F. Belanger, and S. Warnke. 2011. Miniature inverted-repeat transposable element identification and genetic marker development in Agrostis. Crop Sci. 52:854-861.

Amundsen, K. and S. Warnke. 2011. Species relationships in the genus Agrostis based on flow cytometry and MITE-display molecular markers. Crop Sci. 51:1224-1231.

Barkworth, M.E. 2007. Polypogon Desf. In: Barkworth, M.E., L.K. Anderton, K.M. Capels, S. Long, and M.B. Piep (eds.). Manual of grasses for North America. Utah State University Press, Logan, UT.

Barriel, V. 1994. Phylogénies moléculaires et insertions-délétions de nucléotides. C. R. Acad. Sci. Paris ser. 3 317:693-701.

Brilman, L.A. 2001. Utilization of interspecific crosses for turfgrass improvement. Intl. Turfgrass Soc. Res. J. 9:157-161.

Casler, M.D. and R.R. Duncan. 2003. Introduction, p. 3-26. In: Casler, M.D. and Duncan, R.R. (eds.). Turfgrass biology, genetics, and breeding. John Wiley \& Sons, Hoboken, NJ.

Döring, E., J. Schneider, K.W. Hilu, and M. Roser 2007. Phylogenetic relationships in the Aveneae/ Poeae complex (Pooideae, Poaceae). Kew Bull. 62:407-424.

Feliner, G.N. and J.A. Rosselló. 2007. Better the devil you know? Guidelines for insightful utilization of nrDNA ITS in species-level evolutionary studies in plants. Mol. Phylogenet. Evol. 44:911-919.

Fortune, P.M., N. Pourtau, N. Viron, and M.L. Ainouche. 2008. Molecular phylogeny and reticulate origins of the polyploid Bromus species from section Genea (Poaceae). Amer. J. Bot. 95:454-464.

Fulton, T.M., R. Van der Hoeven, N.T. Eannetta, and S.D. Tanksley. 2002. Identification, analysis, and utilization of conserved ortholog set markers for comparative genomics in higher plants. Plant Cell 14:1457-1467.

Ge, S., A. Li, B.-R. Lu, S.-Z. Zhang, and D.-Y. Hong. 2002. A phylogeny of the rice tribe Oryzeae (Poaceae) based on matK sequence data. Amer. J. Bot. 89:1967-1972.

Gillespie, L.J., A. Archambault, and R.J. Soreng. 2006. Phylogeny of Poa (Poaceae) based on trnT-trnF sequence data: Major clades and basal relationships. Aliso 23:420-434.

Guo, Y.-L. and S. Ge. 2005. Molecular phylogeny of Oryzeae (Poaceae) based on DNA sequences from chloroplast, mitochondrial, and nuclear genomes. Amer. J. Bot. 92:1548-1558.

Harvey, M.J. 2007. Agrostis, p. 148-154. In Barkworth, M.E., L.K. Anderton, K.M. Capels, S. Long, and M.B. Piep (eds.). Manual of grasses for North America. Utah State University Press, Logan, UT.

Huelsenbeck, J.P. and F. Ronquist. 2001. MRBAYES: Bayesian inference of phylogeny. Bioinformatics 17:754-755.

Huson, D.H. and D. Bryant. 2006. Application of phylogenetic networks in evolutionary studies. Mol. Biol. Evol. 23:254-267.

Huson, D.H., T. Kloepper, P.J. Lockhart, and M.A. Steel. 2005. Reconstruction of reticulate networks from gene trees. Proc. of RECOMB, Springer, Heidelberg, 2005, LNBI 3500. p. 233-249.

Jones, K. 1956a. Species determination in Agrostis. Part I. Cytological relationships in Agrostis canina L. J. Genet. 54:370-376.

guide strategies aimed at better use of Agrostis germplasm resources with the goal of developing new cultivars that require fewer inputs and have high turf quality. ones, K. 1956b. Species differentiation in Agrostis II. The significance of chromosome pairing in the tetraploid hybrids of Agrostis canina 
subsp. montana Hartm., A. tenuis Sibth. and $A$. stolonifera L. J. Genet. 54:377-393.

Jones, K. 1956c. Species differentiation in Agrostis III. Agrostis gigantea Roth. and its hybrids with A. tenuis Sibth. and A. stolonifera L. J. Genet. 54:394-399.

Kellogg, E.A. 1998. Relationships of cereal crops and other grasses. Proc. Natl. Acad. Sci. USA 95:2005-2010.

Linder, C.R. and L.H. Rieseberg. 2004. Reconstructing patterns of reticulate evolution in plants. Amer. J. Bot. 91:1700-1708.

McBreen, K. and P.J. Lockhart. 2006. Reconstructing reticulate evolutionary histories of plants. Trends Plant Sci. 11:398-404.

Posada, D. and K.A. Crandall. 1998. MODELTEST: Testing the model of DNA substitution. Bioinformatics 14:817-818.

Quintanar, A., S. Castroviejo, and P. Catalán. 2007. Phylogeny of the tribe Aveneae (Pooideae, Poaceae) inferred from plastid trnT-F and nuclear ITS sequences. Amer. J. Bot. 94:15541569.

Reichman, J.R., L.S. Watrud, E.H. Lee, C.A. Burdick, M.A. Bollman, M.J. Storm, G.A. King, and C. Mallory-Smith. 2006. Establishment of transgenic herbicide-resistant creeping bentgrass (Agrostis stolonifera L.) in nonagronomic habitats. Mol. Ecol. 15:4243-4255.

Ronquist, F. and J.P. Huelsenbeck. 2003. MRBAYES 3: Bayesian phylogenetic inference under mixed models. Bioinformatics 19:1572-1574.

Rotter, D., A.K. Bharti, H.M. Li, C. Luo, S.A. Bonos, S. Bughrara, G. Jung, J. Messing, W.A.
Meyer, S. Rudd, S.E. Warnke, and F.C. Belanger. 2007. Analysis of EST sequences suggests recent origin of allotetraploid colonial and creeping bentgrasses. Mol. Genet. Genomics 278:197-209.

Sang, T. 2002. Utility of low-copy nuclear gene sequences in plant phylogenetics. Crit. Rev. Biochem. Mol. Biol. 37:121-147.

Shaw, J., L. Edgar, S. Edward, and S. Randall. 2007. Comparison of whole chloroplast genome sequences to choose noncoding regions for phylogenetic studies in angiosperms: The tortoise and the hare III. Amer. J. Bot. 94:275-288.

Shaw, J., E.B. Lickey, J.T. Beck, S.B. Farmer, W. Liu, J. Miller, K.C. Siripun, C.T. Winder, E.E. Schilling, and R.L. Small. 2005. The tortoise and the hare II: Relative utility of 21 noncoding chloroplast DNA sequences for phylogenetic analysis. Amer. J. Bot. 92:142-166.

Small, R.L., J.A. Ryburn, R.C. Cronn, T. Seelanan, and J.F. Wendel. 1998. The tortoise and the hare: Choosing between noncoding plastome and nuclear $A d h$ sequences for phylogeny reconstruction in a recently diverged plant group. Amer. J. Bot. 85:1301-1315.

Soreng, R.J. and J.I. Davis. 1998. Phylogenetics and character evolution in the grass family (Poaceae): Simultaneous analysis of morphological and chloroplast DNA restriction site character sets. Bot. Rev. 64:1-85.

Soreng, R.J., J.I. Davis, and J.J. Doyle. 1990. A phylogenetic analysis of chloroplast DNA restriction site variation in Poaceae subfam. Pooideae. Pl. Syst. Evol. 172:83-97.
Soreng, R.J., J.I. Davis, and M.A. Voionmaa. 2007. A phylogenetic analysis of Poaceae tribe Poeae sensu lato based on morphological characters and sequence data from three plastid-encoded genes: Evidence for reticulation, and a new classification for the tribe. Kew Bull. 62:425454.

Swofford, D.L. 2002. PAUP*. Phylogenetic Analysis Using Parsimony (*and other methods). Version 4.0b10. Sinauer Associates, Sunderland, MA.

Thompson, J.D., D.G. Higgins, and T.J. Gibson. 1994. CLUSTAL W: Improving the sensitivity of progressive multiple sequence alignment through sequence weighting, position specific gap penalties, and weighted matrix choice. Nucleic Acids Res. 22:4673-4680.

Vergara, G.V. and S.S. Bughrara. 2003. AFLP analyses of genetic diversity in bentgrass. Crop Sci. 43:2162-2171.

Warnke, S. 2003. Creeping bentgrass (Agrostis stolonifera L.), p. 175-185. In: Casler, M.D. and R.R. Duncan (eds.). Turfgrass biology, genetics, and breeding. John Wiley \& Sons, Hoboken, NJ.

Warnke, S.E., D.S. Douches, and B.E. Branham. 1998. Isozyme analysis supports allotetraploid inheritance in tetraploid creeping bentgrass (Agrostis palustris Huds.). Crop Sci. 38:801805.

Watson, L. 1990. The grass family. Poaceae, p. 1-31. In: Chapman, G.P. (ed.). Reproductive versatility in the grasses. Cambridge University Press, Cambridge, MA. 